\title{
Brain-derived nerve growth factor in the cochlea - a reproducibility study
}

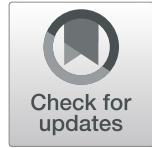

Brian W. Blakley ${ }^{*}$, Michael Seaman and Abdulrahman Alenezi

\begin{abstract}
Objective: Brain-derived nerve growth factor (BDNF) plays an important role in cochlear development so it is plausible that it could restore hearing loss if delivered directly into the cochlea. We wished to confirm our previous report that a single intracochlear injection of brain-derived nerve growth factor (BDNF) was beneficial for hearing in guinea pigs. We wished to assess the reproducibility of our results and assess possible improved methods with a view to developing a clinical treatment for sensorineural hearing loss.

Methods: CDDP was used to create partial hearing loss in 25 guinea pigs. After 30 days the animals underwent $A B R$ testing and unilateral BDNF injection through the round window in one ear and saline injection into the other ear. After allowing possible effects to stabilize, thirty days later, ABR threshold testing was repeated to assess change in threshold.

Results: Final ABR thresholds were $60-70 \mathrm{~dB}$ and were about $11 \mathrm{~dB}$ better in the ears treated with BDNF.

Conclusion: Our original finding that Intracochlear BDNF can improve hearing in guinea pigs was confirmed, but the improvement demonstrated by the methods in this paper is too small for clinical application.
\end{abstract}

Keywords: Hearing, Brain-derived nerve growth factor, Auditory brainstem response, Ototoxicity

\section{Introduction}

Brain-derived nerve growth factor (BDNF) is important for hearing. BDNF is known to play a significant role in cochlear development [1], but its role in adults is less certain [2]. Several authors have reported that BDNF protects against ototoxicity [3] or is important in spiral ganglion cell maintenance $[4,5]$ but a larger, real-world need is to treat chronic sensorineural hearing loss. Some papers have suggested that BDNF expression restores or preserves auditory nerve morphology, electrical brainstem responses or neurophysiology in guinea pigs after ototoxic hearing loss [6-13]. Others have suggested that BDNF application may improve outcomes in cochlear implantation [14].

\footnotetext{
* Correspondence: bblakley@exchange.hsc.mb.ca

Department of Otolaryngology, University of Manitoba, Winnipeg, Manitoba R3A 1R9, Canada
} $\triangle B M C$

(c) The Author(s). 2020 Open Access This article is licensed under a Creative Commons Attribution 4.0 International License, which permits use, sharing, adaptation, distribution and reproduction in any medium or format, as long as you give appropriate credit to the original author(s) and the source, provide a link to the Creative Commons licence, and indicate if changes were made. The images or other third party material in this article are included in the article's Creative Commons licence, unless indicated otherwise in a credit line to the material. If material is not included in the article's Creative Commons licence and your intended use is not permitted by statutory regulation or exceeds the permitted use, you will need to obtain permission directly from the copyright holder. To view a copy of this licence, visit http://creativecommons.org/licenses/by/4.0/. The Creative Commons Public Domain Dedication waiver (http://creativecommons.org/publicdomain/zero/1.0/) applies to the data made available in this article, unless otherwise stated in a credit line to the data.

Gene therapy is one consideration. Ongoing research involving promising, molecular biological approaches to hearing loss may provide treatment someday but knowledge of gene control and methods of administration of genetic modifiers is lacking. Could simple injection of BDNF to the cochlea achieve positive results? The answer to this question is unclear but it seems important to address a possible simple solution for hearing loss. After all, the research findings that relate to BDNF and hearing are based on the expression of BDNF, not control of its activity. The possibility that direct injection of BDNF into the cochlea deserves study as a possible clinical intervention for hearing loss.

There is uncertainty regarding BDNF research. Much of the BDNF research focuses on hair cell survival or in vitro findings, not actual hearing. BDNF may result in morphologic improvements but not hearing in pigeons [15]. For clinicians, the glaring deficiency in the literature seems to be the lack of evidence that hearing is 
actually improved. In some previous studies BDNF was applied to the round window niche, sometimes over several weeks. To us this seemed unlikely to succeed considering the blood-labyrinth barrier and the fact that BDNF is a high molecular weight substance that may not pass through the round window. In addition, many studies assess the effect of BDNF or some other agent only a few days after exposure to an ototoxic agent. This may not provide valid information if the hearing loss has not stabilized. In previous publications we reported some data hoping that our methods would be useful in restoring hearing [16, 17], but data conflict so we undertook more studies to validate and possibly improve on our previous results.

We considered some improvements on our initial design. In our previous study [16] we used intraperitoneal cisplatin (cisdiaminedichloroplatinum or CDDP) $15 \mathrm{mg} /$ $\mathrm{kg}$ to create hearing loss, then drilled a hole through the cochlea, possibly violating the stria vascularis, to deliver 0.05 micrograms of BDNF as a single application. Six of 16 guinea pigs had to be euthanized, due to weight loss, so we were left with 11 animals. We desired a study with more surviving animals. We have found that CDDP 4 $\mathrm{mg} / \mathrm{kg}$ on alternate days for 3 doses (total dose $12 \mathrm{mg}$ / $\mathrm{kg}$ ) resulted in moderate hearing loss, but minimal mortality. In addition, the "soft approach" cochlear implantation [18] led us to suspect that we would find better results if we delivered the BDNF through the round window, rather than drilling into the cochlea.

Our lab has previously explored the possibility that simply injecting the BDNF into the cochlea is associated with better hearing. If such a simple treatment were successful, the application could help millions. The purpose of this study was to assess the reproducibility and possibly confirm our previous findings. In our previous study we reported that a single intracochlear injection of BDNF resulted in auditory brainstem response (ABR) thresholds across several frequencies that were from 2 to $27 \mathrm{~dB}$ better than saline-injected ears [16]. We found these results encouraging and hoped that, with modification, they could be applicable clinically to humans if the techniques are effective. In a subsequent study using more traumatic techniques than herein, we found that click thresholds were not statistically different in ears treated with BDNF [17]. We felt that the differences between pure tone and click thresholds were conflicting results that must be resolved with this study.

Neurotrophins such as BDNF act by signaling through tyrosine kinases, reducing the formation of oxygen free radicals and up-regulation of apoptotic genes and mitigation of intracellular calcium $\left(\mathrm{Ca}^{2+}\right)$ activity. BDNF acts on the TrkB receptor. Mice that lack either BDNF or the TrkB receptor have no hearing [19].

Several studies have suggested that BDNF could be useful in preservation of auditory structure or function in animals [13, 20-22] and humans [23] but the technique has not seen clinical application to date [24]. BDNF may be the most important neurotrophin for maintenance of cochlear neurons $[25,26]$. In fact, the "neurotrophin factor hypothesis" posits that all agerelated degeneration in the central nervous system results from deficiencies of neurotrophins [4].

In vitro, BDNF has been shown to be important BDNF seems to be the most important in the cochlea [2,27] and for cochlear development and maintenance of cochlear histology in adult life [23, 28, 29]. BDNF is upregulated in the organ of Corti but not auditory neurons in gerbils, suggesting that BDNF may mitigate cochlear hearing losses to a greater extent that those due to auditory nerve degeneration [30].

There is reason to suspect that the activity of BDNF on cochlear cells is not under strict genetic control and a single application of BDNF may be effective [31].

If this project is successful it appears that BDNF could be applied systemically to humans. Clinical trials conducted using daily BDNF to treat amyotrophic lateral sclerosis [32, 33], Guillian-Bare [34], and diabetic neuropathy [35] have suggested favorable outcomes for those disorders. Nausea and vomiting was the most common side effect of systemic but not intrathecal administration. Hearing was not assessed in those trials but the studies illustrate that BDNF could be safely delivered to humans. The inner ear is relatively isolated from systemic circulation by the blood-labyrinth barrier so it seems likely that systemic toxicity should be minimal with intracochlear administration. BDNF has a molecular weight of $27.5 \mathrm{kDa}$ which is too large to allow BDNF to pass through the blood-labyrinth barrier. Systemic administration of BDNF would result in low concentrations and likely induce systemic side effects so a local method of drug administration seems optimal. The simplest method of introducing drugs into the inner ear locally would seem to be simple injection through the round window, plugging the needle opening after injection [36].

An effective neurotrophin should require time to achieve complete effect. Ruan et al. [37] reported that BDNF supported cochlear histology 30 days after administration of kanamycin to induce ototoxicity but not 15 days. BDNF "rescue" may be effective even if administered more than 2 weeks after inducing hearing loss [6] or longer [9].

Our findings mimic those of Radeloff and Smolders [15] who delivered BDNF over 8 weeks with osmotic micropumps but found that the insertion trauma outweighed the positive effects of the BDNF. As clinicians, we suspect that chronical implantation of micropumps would create a perilymph fistula and subsequent hearing loss and favor intermittent applications. 
For this project we adopted some of the principles of "soft technique" for cochlear implantation that were intended to preserve residual hearing. Those relevant to this project these include slow, gentle, shallow injection, use of the round window rather than a cochleostomy with a drill [38], and avoiding the entry of blood into the cochlea $[18,38]$.

This study is our attempt to re-produce the results of our previous study using more animals, a lower, more tolerable dose of CDDP and less traumatic, round window delivery of BDNF. The protocol was approved by the University of Manitoba Animal Ethics Research Committee.

\section{Methods}

Our ABR protocol has been described previously [16]. Pure tone ABR threshold testing was performed under ketamine anesthesia at $3 \mathrm{~K}, 6 \mathrm{~K}, 12 \mathrm{~K}$ and $24 \mathrm{~K} \mathrm{~Hz}$ using the Intelligent Hearing Systems platform for evoked potentials. After baseline thresholds (day 0) in dB SPL were obtained, intraperitoneal CDDP $(4 \mathrm{mg} / \mathrm{kg}$ X 3 doses on alternate days for a total dose of $12 \mathrm{mg} / \mathrm{kg}$ ) was administered to create a partial sensorineural hearing loss. After allowing 30 days for the hearing to stabilize (day 30), ABR testing was performed again, and under the same anesthetic, the left round window in each animal was injected with 0.05 micrograms of BDNF (Sigma corp) and the same volume $(0.01 \mathrm{cc})$ of saline injected into the right round window. These injections were accomplished after removing some of the tympanic membrane and part of the scutum to visualize the round window under a microscope. An opening in the round window was created by puncturing it with a sharp pick. The injections were performed by placing a finely calibrated gas chromatograph syringe through the opening in the round window into the cochlea. A small piece of fat was then used to seal the round window. Healing of the tympanic membranes occurred over 10-14 days and was verified by otoscopy. Thirty days after the injections (day 60) ABR was performed again to assess the final hearing result. The timeline is shown in Fig. 1.

ABR thresholds were entered into a database and Analysis of Variance for Repeated Measures was performed using SPSS v24 software and a significance level of $p=$
0.05 to assess the differences in threshold across the treated versus non-treated ears over the days of testing and across the four frequencies tested. Contrasts were employed to determine the significance of differences in threshold according to day number $(0,30$ or 60$)$.

\section{Results}

Figure 2 illustrates the changes in ABR threshold for the four frequencies tested at days 0 (baseline), day 30 (after $\mathrm{CDDP}$ ), and day 60 (after BDNF/saline) rounding ABR thresholds and 95\% CI results to two significant figures. Mauchly's test of sphericity was not violated $(p=0.254)$ for ABR thresholds by day. ANOVA results indicates that differences across frequencies were not statistically significant $(p=0.088)$ so all frequencies were included together in further analysis.

Threshold differences were not significantly different between the treated and non-treated ears at days 0 or 30 , but at day 60 (30 days after $\mathrm{BDNF} /$ saline treatment) the traces diverged significantly. Figure 3 illustrates the final ABR thresholds for BDNF-treated and salinetreated ears. Statistically significant differences in ABR threshold were demonstrated between the BDNF-treated and saline-treated ears $(p=0.034)$. Across all frequencies final, rounded ABR thresholds in BDNF-treated ears on day 60 were $60+/-23 \mathrm{~dB}$ (mean $+/-95 \% \mathrm{CI}$ ) in BDNFtreated ears and $71+/-20 \mathrm{~dB}$ in the saline-treated ears for a mean difference of $11 \mathrm{~dB}$.

CDDP induced a mean increase in ABR threshold on both sides of $9 \mathrm{~dB}$ across all frequencies. Intracochlear injection increased the thresholds further by an average of $16 \mathrm{~dB}(21 \mathrm{~dB}$ on the saline side and $13 \mathrm{~dB}$ on the BDNF side).

\section{Discussion}

Several findings deserve discussion.

First, our results indicate that intracochlear BDNF is associated with lower thresholds of about $11 \mathrm{~dB}$. The results of this study are consistent with some of our previous work, indicating a small difference in threshold in ears treated with BDNF [16]. We were hoping to demonstrate that intracochlear BDNF treatment can restore hearing. While a gain of $11 \mathrm{~dB}$ is desirable this gain is

\section{Timeline}

\begin{tabular}{|c|c|c|c|c|}
\hline Baseline ABR & & & $A B R$ & $A B R$ \\
\hline $\begin{array}{l}\text { Then CDDP } \\
1^{\text {st }} \text { dose }\end{array}$ & $\begin{array}{c}\text { CDDP } \\
2^{\text {nd }} \text { dose }\end{array}$ & $\begin{array}{c}\text { CDDP } \\
3^{\text {rd }} \text { dose }\end{array}$ & $\begin{array}{l}\text { then saline or } \\
\text { BDNF }\end{array}$ & euthanize \\
\hline
\end{tabular}

Fig. 1 Timeline for experiments. After initial auditory brainstem response (ABR) testing the 25 guinea pigs received cisplatin (CDDP, $4 \mathrm{mg} / \mathrm{kg} X 3$ doses on alternate days for a total of $12 \mathrm{mg} / \mathrm{kg}$ ). After allowing hearing loss to stabilize for a month either BDNF or saline was injected into the round window. ABR thresholds were obtained another month after that 


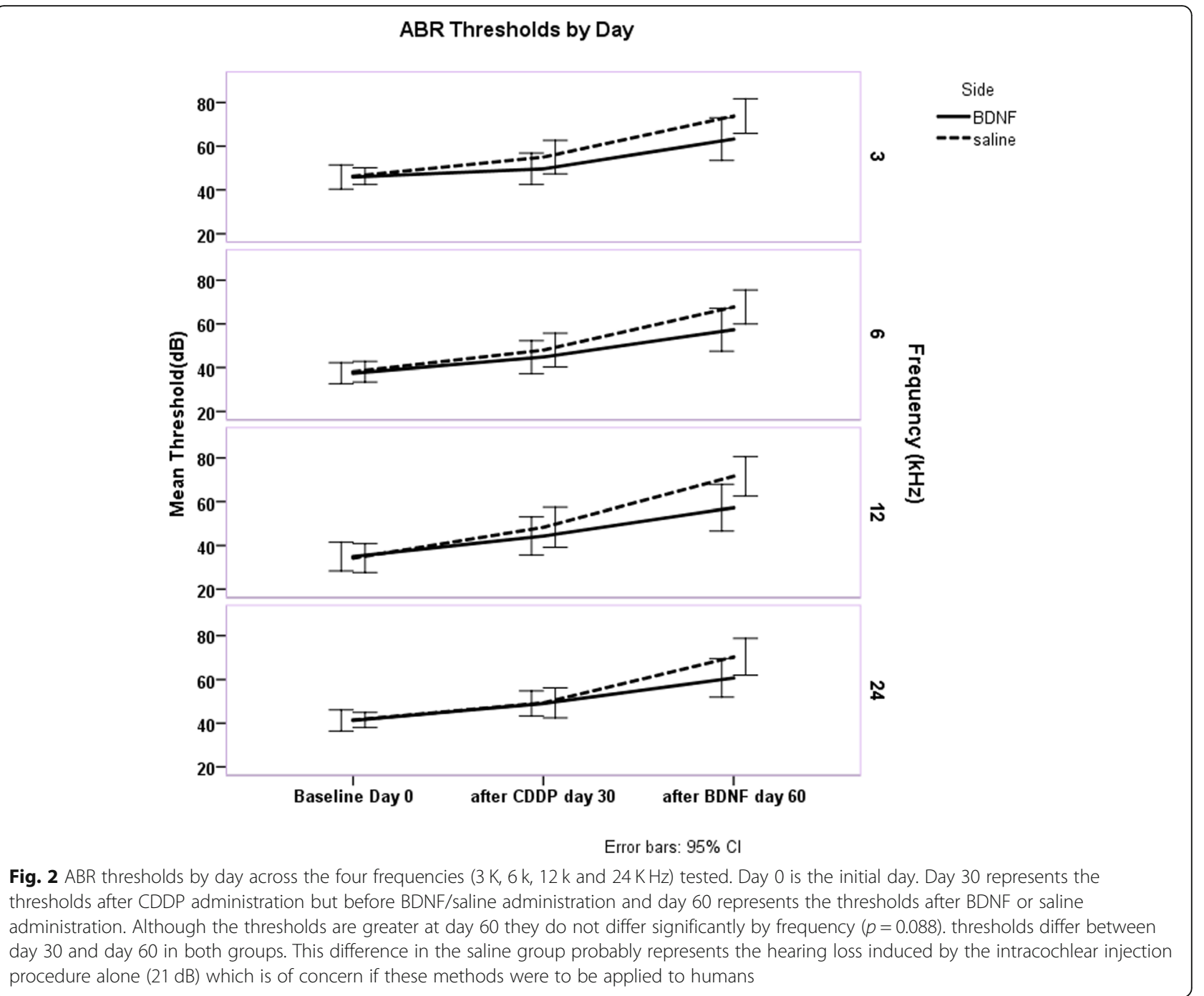

not adequate to apply clinically. Thresholds are still far from normal. It appears that a single treatment of BDNF delivered as we have done here, will not provide treatment for sensorineural hearing loss as we had hoped. Perhaps multiple applications, a different dose or other method would show more response. We plan to pursue a multiple dose regimen in future work.

Second, the $11 \mathrm{~dB}$ improvement in hearing did not overcome the loss induced by the intracochlear injection, highlighting the importance of controls in research. The effect of the injection procedure is evident as the increase in threshold between 30 and 60 days in both the BDNF- and the saline-treated ears. This finding would seem to be important for any agent injected into the cochlea for the purpose of improving hearing.

Third, it is odd that the ABR thresholds did not differ by frequency as one might expect from the human literature. In this project as well as our previous work has also found that, in rodents, CDDP affects all thresholds across the range of frequencies tested. Differences between human and rodent hearing should be considered if this research is to be applied to humans. For example, rodents have excellent hearing in higher frequency ranges than humans, perhaps up to $40 \mathrm{kHz}$. We have sampled some of both ranges. Anesthetic time limits the feasibility of testing at very many frequencies.

Fourth, the CDDP did not create as much hearing loss as it has in past work in our lab [39]. Typically, we expect to induce a loss of about 25-30 dB with the CDDPregimen used here. This illustrated the variability in animal research models. Perhaps with large hearing losses our results would be different.

Although it CDDP is commonly thought to affect higher frequencies more than lower ones this was not reflected in our data. ABR thresholds at day 30 were similar across frequencies. We have found this in other studies as well [39]. 


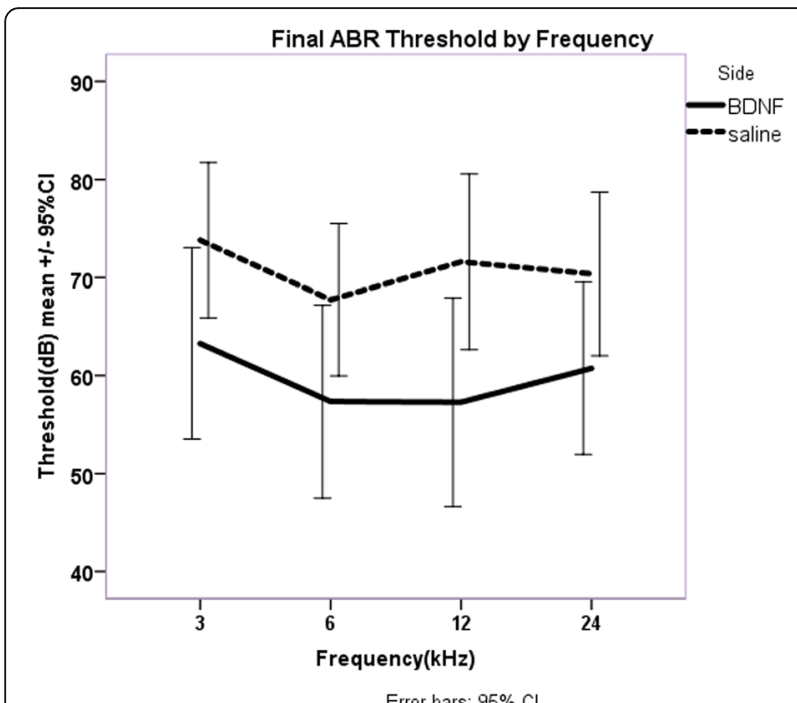

Error bars: $95 \% \mathrm{Cl}$

Fig. 3 Averaged final thresholds at day 60 with all frequencies included. The mean difference in ABR thresholds for BDNF-treated ears (60 were $60+/-23 \mathrm{~dB}$ ) versus saline-treated ears $(71+/-20 \mathrm{~dB})$ was significant $(p=0.034)$. The mean difference was $11 \mathrm{~dB}$, which is less than the increase in threshold resulting from the intracochlear injection

\section{Conclusion}

Intracochlear BDNF injection can benefit hearing in guinea pigs but does not overcome the hearing loss induced by the injection itself. The methods as used in this paper are inadequate for clinical application.

\section{Acknowledgements}

None.

This project was approved by the University of Manitoba Animal Ethics Committee.

\section{Declarations}

For "Brain-derived Nerve Growth Factor in the Cochlea - A Reproducibility Study" by Blakley BW, Seaman M, and Alenezi A.

\section{Authors' contributions}

Brian Blakley - conceived the idea, planned the project, secured funding, participated significantly in data collection, wrote the paper. Michael Seaman -Medical student working on a summer research project. He participated significantly in data collection, development of the project and offered comments on the paper. Abdulrahman Alenezi - Resident in Otolaryngology. Participated in writing, data organization and analysis. The author(s) read and approved the final manuscript.

\section{Funding}

Internal Department and personal funds.

\section{Competing interests}

None.

Received: 8 November 2019 Accepted: 24 May 2020

Published online: 05 June 2020

\section{References}

1. Despres G, Romand R. Neurotrophins and the development of cochlear innervation. Life Sci. 1994;54:1291-7.

2. Hafidi A. Distribution of BDNF, NT-3 and NT-4 in the developing auditory brainstem. Int J Dev Neurosci. 1999;17:285-94.
3. Maeta M, Anniko M. Protective Efect of brain-derived Neurotrophic factor against the ototoxicity of Pseudomonas aeruginosa exotoxin a. Acta Otolaryngol. 2003;123:14-9.

4. Miller JM, Miller AL, Yamagata T, Bredberg G, Altschuler RA. Protection and regrowth of the auditory nerve after deafness: neurotrophins, antioxidants and depolarization are effective in vivo. Audiol Neurootol. 2002;7:175-9.

5. Shinohara T, Bredberg G, Ulfendahl M, et al. Neurotrophic factor intervention restores auditory function in deafened animals. Proc Natl Acad Sci U S A. 2002;99:1657-60.

6. Yamagata T, Miller JM, Ulfendahl M, et al. Delayed neurotrophic treatment preserves nerve survival and electrophysiological responsiveness in neomycin-deafened Guinea pigs. J Neurosci Res. 2004;78:75-86.

7. McGuinness SL, Shepherd RK. Exogenous BDNF rescues rat spiral ganglion neurons in vivo. Otol Neurotol. 2005;26:1064-72

8. Wissel K, Wefstaedt P, Miller JM, Lenarz T, Stover T. Differential brain-derived neurotrophic factor and transforming growth factor-beta expression in the rat cochlea following deafness. Neuroreport. 2006;17:1297-301.

9. Miller JM, Le Prell CG, Prieskorn DM, Wys NL, Altschuler RA. Delayed neurotrophin treatment following deafness rescues spiral ganglion cells from death and promotes regrowth of auditory nerve peripheral processes: effects of brain-derived neurotrophic factor and fibroblast growth factor. J Neurosci Res. 2007:85:1959-69.

10. Rejali D, Lee VA, Abrashkin KA, Humayun N, Swiderski DL, Raphael Y. Cochlear implants and ex vivo BDNF gene therapy protect spiral ganglion neurons. Hear Res. 2007;228:180-7.

11. Glueckert $R$, Bitsche M, Miller JM, et al. Deafferentation-associated changes in afferent and efferent processes in the Guinea pig cochlea and afferent regeneration with chronic intrascalar brain-derived neurotrophic factor and acidic fibroblast growth factor. J Comp Neurol. 2008;507:1602-21.

12. Sun W, Salvi RJ. Brain derived neurotrophic factor and neurotrophic factor 3 modulate neurotransmitter receptor expressions on developing spiral ganglion neurons. Neuroscience. 2009;164:1854-66.

13. Zhai SQ, Guo W, Hu YY, et al. Protective effects of brain-derived neurotrophic factor on the noise-damaged cochlear spiral ganglion. J Laryngol Otol. 2011;125:449-54.

14. Shepherd RK, Coco A, Epp SB, Crook JM. Chronic depolarization enhances the trophic effects of brain-derived neurotrophic factor in rescuing auditory neurons following a sensorineural hearing loss. J Comp Neurol. 2005:486:145-58.

15. Radeloff A, Smolders JW. Brain-derived neurotrophic factor treatment does not improve functional recovery after hair cell regeneration in the pigeon. Acta Otolaryngol. 2006;126:452-9.

16. Meen E, Blakley B, Quddusi T. Brain-derived nerve growth factor in the treatment of sensorineural hearing loss. Laryngoscope. 2009;119:1590-3.

17. Meen E, Blakley B, Quddusi T. Does intracochlear brain-derived nerve growth factor improve auditory brainstem click thresholds in sensorineural hearing loss? J Otolaryngol Head Neck Surg. 2010;39:232-5.

18. Friedland DR, Runge-Samuelson C. Soft cochlear implantation: rationale for the surgical approach. Trends Amplif. 2009;13:124-38.

19. Fritzsch B, Silos-Santiago I, Bianchi LM, Farinas I. The role of neurotrophic factors in regulating the development of inner ear innervation. Trends Neurosci. 1997;20:159-64.

20. Atkinson PJ, Wise AK, Flynn BO, et al. Neurotrophin gene therapy for sustained neural preservation after deafness. PLoS One. 2012:7:e52338.

21. Fukui $H$, Wong $H T$, Beyer $L A$, et al. BDNF gene therapy induces auditory nerve survival and fiber sprouting in deaf Pou4f3 mutant mice. Sci Rep. 2012;2:838.

22. Leake PA, Stakhovskaya O, Hetherington A, Rebscher SJ, Bonham B. Effects of brain-derived neurotrophic factor (BDNF) and electrical stimulation on survival and function of cochlear spiral ganglion neurons in deafened, developing cats. J Assoc Res Otolaryngol. 2013;14:187-211.

23. Qun LX, Pirvola U, Saarma M, Ylikoski J. Neurotrophic factors in the auditory periphery. Ann N Y Acad Sci. 1999;884:292-304.

24. Havenith S, Versnel H, Klis SF, Grolman W. Local delivery of brain-derived neurotrophic factor on the perforated round window membrane in Guinea pigs: a possible clinical application. Otol Neurotol. 2015;36:705-13.

25. Agerman $\mathrm{K}$, Hjerling-Leffler J, Blanchard MP, et al. BDNF gene replacement reveals multiple mechanisms for establishing neurotrophin specificity during sensory nervous system development. Development. 2003:130:1479-91.

26. Schimmang T, Tan J, Muller M, et al. Lack of Bdnf and TrkB signalling in the postnatal cochlea leads to a spatial reshaping of innervation along the tonotopic axis and hearing loss. Development. 2003;130:4741-50. 
27. Budenz CL, Wong HT, Swiderski DL, Shibata SB, Pfingst BE, Raphael Y. Differential effects of AAV.BDNF and AAV.Ntf3 in the deafened adult guinea pig ear. Sci Rep. 2015;5:8619.

28. Singer W, Panford-Walsh R, Knipper M. The function of BDNF in the adult auditory system. Neuropharmacology. 2014;76 Pt C:719-28.

29. Johnson Chacko L, Blumer MJF, Pechriggl E, et al. Role of BDNF and neurotrophic receptors in human inner ear development. Cell Tissue Res. 2017;370:347-63.

30. Medd AM, Bianchi LM. Analysis of BDNF production in the aging gerbil cochlea. Exp Neurol. 2000;162:390-3.

31. Sly DJ, Campbell L, Uschakov A, Saief ST, Lam M, O'Leary SJ. Applying Neurotrophins to the round window rescues auditory function and reduces inner hair cell Synaptopathy after noise-induced hearing loss. Otol Neurotol. 2016;37:1223-30.

32. Ochs G, Penn RD, York M, et al. A phase I/II trial of recombinant methionyl human brain derived neurotrophic factor administered by intrathecal infusion to patients with amyotrophic lateral sclerosis. Amyotroph Lateral Scler Other Motor Neuron Disord. 2000;1:201-6.

33. A controlled trial of recombinant methionyl human BDNF in ALS: The BDNF Study Group (Phase III). Neurology. 1999;52(7):1427-33. https://doi.org/10. 1212/wnl.52.7.1427.

34. Bensa S, Hadden RD, Hahn A, Hughes RA, Willison HJ. Randomized controlled trial of brain-derived neurotrophic factor in Guillain-Barre syndrome: a pilot study. Eur J Neurol. 2000;7:423-6.

35. Wellmer A, Misra VP, Sharief MK, Kopelman PG, Anand P. A double-blind placebo-controlled clinical trial of recombinant human brain-derived neurotrophic factor (rhBDNF) in diabetic polyneuropathy. J Peripher Nerv Syst. 2001;6:204-10.

36. Plontke SK, Hartsock JJ, Gill RM, Salt AN. Intracochlear drug injections through the round window membrane: measures to improve drug retention. Audiol Neurootol. 2016;21:72-9.

37. Ruan RS, Leong SK, Mark I, Yeoh KH. Effects of BDNF and NT-3 on hair cell survival in Guinea pig cochlea damaged by kanamycin treatment. Neuroreport. 1999;10:2067-71.

38. Fishman AJ, Moreno LE, Rivera A, Richter CP. CO(2) laser fiber soft cochleostomy: development of a technique using human temporal bones and a Guinea pig model. Lasers Surg Med. 2010:42:245-56.

39. Leitao DJ, Blakley BW. Quantification of sodium thiosulphate protection on cisplatin-induced toxicities. J Otolaryngol. 2003;32:146-50.

\section{Publisher's Note}

Springer Nature remains neutral with regard to jurisdictional claims in published maps and institutional affiliations.

Ready to submit your research? Choose BMC and benefit from:

- fast, convenient online submission

- thorough peer review by experienced researchers in your field

- rapid publication on acceptance

- support for research data, including large and complex data types

- gold Open Access which fosters wider collaboration and increased citations

- maximum visibility for your research: over $100 \mathrm{M}$ website views per year

At $\mathrm{BMC}$, research is always in progress.

Learn more biomedcentral.com/submissions 